INSTITUT NATIONAL DE LA STATISTIQUE ET DES ETUDES ECONOMIQUES

Série des Documents de Travail du CREST

(Centre de Recherche en Economie et Statistique)

\title{
$n^{\circ}$ 2005-17
}

\section{An Optimal Anti-Drug \\ Law Enforcement Policy}

\author{
S. PORET ${ }^{1}$
}

Les documents de travail ne reflètent pas la position de l'INSEE et n'engagent que leurs auteurs.

Working papers do not reflect the position of INSEE but only the views of the authors.

\footnotetext{
${ }^{1}$ INRA-LORIA and CREST-LEI.

INRA-LORIA, 65 boulevard de Brandebourg, 94205 Ivry-sur-Seine Cedex. France.

Tel. : +33 (0)1 495969 07. Fax : +33 (0)1 495969 98. Email : poret@ivry.inra.fr
} 


\title{
Résumé
}

Cet article modélise une politique optimale d'application des lois anti-drogues, visant à réduire le coût social lié aux drogues. On prend en compte le coût net d'application de la loi, le dommage social, et le surplus des agents. Nous considérons des filières de distribution verticalement organisées avec deux niveaux : trafiquants et détaillants. Les deux questions sont quel type de vendeurs les autorités doivent poursuivre, les trafiquants ou les revendeurs, et quelle sanction un vendeur doit payer en cas d'arrestation. Le niveau optimal de l'amende dépend du type de vendeurs arrêtés, de la probabilité d'arrestation au moment d'une transaction, et de la sensibilité du dommage social aux quantités consommées. Nous montrons que fixer l'amende à son niveau maximum est rarement optimal.

Mots Clés : drogues illicites, réduction des dommages, mise en œuvre des lois, structure verticale.

Classification JEL : D43, K42, L13.

\begin{abstract}
This paper presents a model of an optimal anti-drug law enforcement policy, whose objective is the reduction of drug-related social cost, including the net cost of law enforcement, the social harm, and the surplus of agents. We consider a vertically organized distribution system with two levels: traffickers and retailers. The two questions are which type of sellers authorities must pursue, traffickers or retailers, and which sanction a seller has to pay in case of arrest. The optimal level of fine depends on the type of sellers arrested, the probability of arrest at the time of a transaction, and the sensitivity of the harm to consumed quantities. We show that the maximum fine is rarely optimal.
\end{abstract}

Keywords: illicit drug policy, harm reduction, law enforcement, vertical market structure

JEL Classification: D61, K42, L11, L13. 


\section{Introduction}

The illicit drug problem is currently, in many countries, one of the main social concerns. The numerous anti-drug policies set up in all countries and the three international conventions are a proof of the interest carried to this question by governments and international organizations. ${ }^{1}$

In the sixties and seventies, faced with the appearance of new products, such as LSD, and faced with the increase in drug consumption among the young, numerous countries legislate about the use and selling of some drugs (see, for example, the Drug Abuse Control Act of 1968 and the Comprehensive Drug Abuse and Control Act of 1970 in the United States and the French law of 1970). In the eighties, anti-drug laws became harder and the enforcement more repressive. The law enforcement of the use and trade of some drugs still represent an increasing part of public expenditures in the anti-drug policy, to the detriment of prevention, information, and treatment. The United States have started the 'War on Drugs' with the objective of a drug free world. After having gone through a sizeable growth since 1988 (4.6 billions of dollars in 1988, 14.4 in 1997), the federal budget for the fight against drugs adds up to 18.1 billions of dollars in 2001, with always a distribution of two-thirds for law enforcement and a third for prevention and treatment (US-ONDCP, 2002).

The United Nations International Drug Control Programme, through its director Pino Arlacchi, took up this objective in 1998, on the occasion of the United Nations General Assembly Special Session to Counter the World Drug Problem Together (UNGASS). Five years after having launched this ambitious plan of illicit drugs eradication, planned over ten years, the United Nations' Commission for Narcotic Drugs met in April 2003 in Vienna, in Austria. Its intermediate assessment is ambiguous. The ministers and delegates of 124 countries approved a report which describes as encouraging the progress obtained to eliminate or significantly reduce the illicit production of cocaine, heroin, and marijuana, the trade and the demand for psychotropic substances, including synthetic drugs, before then 2008 .

A growing number of nations currently adopt to the UN's prohibitionnist precept. But official statistics do not confirm the expected results. As a

\footnotetext{
${ }^{1}$ The international conventions are the followings: the United Nations Single Convention on Narcotic Drugs (New York, 1961, amended 1972), the Convention on Psychotropic Substances (Vienna, 1971) and the Convention against Illicit Traffic in Narcotic Drugs and Psychotropic Substances (Vienna, 1988).
} 
matter of fact, the more repressive drug policy does not succeed in stemming the increase in drug production and consumption. Admittedly, coca crops dropped in Colombia in 2002, but overall in the Latin region the production remained stable, and even higher than that of 1985. Concerning heroin, the year 2001 was remembered by a near total eradication of the poppy in Afghanistan. This success, the only tangible one, is only one effect of the dictatorship of the Taliban. From the fall of the regime, the production of poppy found its high level, with more than 3000 tons, twice as much as in 1990. The seizures and consumption of cannabis appreciably declined in 2001. At the same time, one notes a strong growth in the trade of amphetamines, ecstasy and their derivatives, with an explosion of use in poor countries. At the present time, nothing makes it possible to imagine an eradication for 2008. Besides, the joint Governments' declaration recognizes that progress is unequal.

In parallel to the UN's works, some Non-Governmental Organizations hold a counter-meeting. They contest the UN's strategy and describe the actual anti-drug policy as total failure. They point out the fact that the stringent drug control policy is a large source of social harms. In the majority of countries, anti-drug policies have focused on the reduction of the number of users, indeed even a 'zero tolerance' policy, by law enforcement regimes reducing demand or supply. Notwithstanding recently, in some countries, the goal of drug policy moves towards a policy of reduction of harms related to illicit drug or, briefly, harm reduction policy. This is a policy alternative to the current repressive regime, even if it sticks to prohibition.

The term of harm reduction is ambiguous and requires some comments. In policies put in practice by some governments, harm reduction is a set of practical strategies that reduce negative consequences of drug use. Harm reduction refers to measures aimed at reducing the harm associated with drug use without necessarily requiring a reduction in consumption. It consists of some programs such as needle exchange, methadone maintenance treatment, controlled prescription of heroin. Some researchers, such as Caulkins (1996), define harm reduction as the principle that drug policy makers should seek to minimize the total harm associated with the production, distribution, consumption and control of drugs. The objective is then to reduce the whole damage related to illicit drugs. This principle is parallel to a cost-benefit analysis. The harm reduction policy corresponds to a second-best public policy. Caulkins and Reuter (1997) point out that it is a matter of maximizing the social welfare or, in the same way, minimizing the social cost, related 
to illicit drugs. Kopp (1997) defines it as the best public intervention which minimizes the drug social cost under the constraint of the prohibition law.

The question of determining the optimal law enforcement policy for illicit drugs has not been much dealt with. The literature on drug market has studied the illicit drug problem with a positive approach. Few authors have proposed explanations for the inefficiency of the use reduction policy, by focusing on either the users (see Caulkins, 1993; Lee, 1993) or the sellers (see Chiu, Mansley and Morgan, 1998; Mansour, Marceau and Mongrain, 2001; Skott and Jepsen, 2002; Poret, 2002; Poret and Téjédo, 2003).

In this paper, we define an objective for the anti-drug policy with a strict utilitarian analysis. It is to minimize the net social cost related to illicit drugs, which includes the net cost of the law enforcement, the harm related to the trade and consumption of illegal drugs, and the surplus of agents implicated in trade or use. From a theoretical point of view, this paper is related to several branches of the literature: industrial organization, economics of crime, and public economy. The purpose of this paper is to develop a normative approach of the illicit drug problem, in a context of prohibition, by considering a harm reduction policy, instead of a use reduction policy. For that, we propose an extension of the model developed in Poret (2002), which focuses on drugs sellers' transactions costs related to law enforcement and the structure of the illicit drug market. We compare the optimal law enforcement, more precisely the optimal fine, in terms of net social cost, according to the pursued members of the distribution chain, traffickers or retailers, the sensitivity of the social harm to drug market quantity, and the probability of detection at the time of a transaction. We show that the maximal fine is not always optimal, especially not when the main harm related to drugs is the health externalities.

Some of the results of this paper are very close to Becker, Grossman and Murphy (2004). They study the effects of drug law enforcement in focusing the elasticity of demand for these goods and they assume that drugs are supplied by a competitive drug industry. Optimal expenditures on apprehension of drugs sellers crucially depend on this parameter of the demand and also on the extent of the difference between the social and private value of consumption of illicit drugs. In particular, when the demand is inelastic, it does not pay to enforce any prohibition unless social value is negative and more merely less than the private value.

The paper is organized as follows. The basic framework is presented in Section 2. Section 3 describes the social cost related to illicit drugs. Section 
4 presents results and compares the two law enforcement systems. Section 5 concludes.

\section{The basic framework}

We use the framework of Poret (2002) to model the drug distribution market. It is made up of consumers, a vertically organized distribution network, and the drug law enforcement authority.

\subsection{Hypotheses}

As Marceau, Mansour and Mongrain (2001) and Clark (2003), we consider a global linear inverse demand function $p(x)=v-x$, with $p$ the drug retail price, $v$ the number of potential consumers, and $x$ the drug quantity. When the drug retail price increases, the quantity consumed falls, because the price elasticity of demand is far from being null, despite conventional wisdom about this question. ${ }^{2}$ We do not want to capture the addictive behaviors, which concern only a part of users. Estimations suggest that only $5 \%$ of the people who tested heroin, that creates a strong physical and psychological dependence, became dependent on this product (Prinz, 1997).

We consider a vertically organized market with two levels: the upstream level consisting of $m$ identical traffickers and the downstream level consisting of $n$ identical retailers $(m \leq n)$. We assume that the competition in intermediate and final good markets is à la Cournot $^{3}$ and that the marginal production cost is normalized to zero. Let $x_{j}$ be the quantity sold by a trafficker $j(j=1, \ldots, m)$ and $x_{i}$ the quantity sold by a retailer $i(i=1, \ldots, n)$. We consider only unitary demand at the consumer level. ${ }^{4}$ Thus, $x_{i}$ is also the number of consumers served by a retailer $i$, or also the number of transactions made by him/her, and $x_{i j}=\frac{x_{j}}{x_{i}}$ the number of retailers served by a

\footnotetext{
${ }^{2}$ See Becker, Grossman and Murphy (1991) for a theoretical analysis and Caulkins (1995), Saffer and Chaloupka (1999), Breteville-Jensen and Biørn (2001) for empirical studies.

${ }^{3}$ The competition on the illicit drug market is not very intense, especially in small areas. Moreover, sellers do not directly raise drug price. They diminish the quantity of pure product per dose, that is, the quality of the drug sold.

${ }^{4}$ We assume that the drug consumption is depenalized. This has a direct effect on the structure of sales: to avoid being confused with a seller, who is punished in case of arrest, each consumer buys only one unit of drug when he meets with his dealer.
} 
trafficker $j$, that is, the number of transactions made by him/her.

Enforcement authorities have two law enforcement instruments to fight against such illicit activities as drug trade: resources to arrest and convict sellers and penalties for drug sale. Authorities have some limited resources $D$ to detect retailers or traffickers. This spending determines the probability $q$ of arrest and conviction at the time of a transaction with a customer. ${ }^{5}$ The time of the arrest is a geometrically distributed random variable with a probability of success equal to $q$. Besides, transactions are identical and independent. Thus the probability of being arrested during $t$ transactions is equal to $1-$ $(1-q)^{t}$. Once he has been arrested, the seller can not continue selling the product. The probability of arrest is an increasing, concave function of the number of transactions.

The second tool, the sanction paid by the seller in case of arrest and conviction, is a linear function of the quantity exchanged at the time of a transaction $x$ and of the unitary sanction $s$ : $s x$ (Becker, Grossman, Murphy, 2004). This representation of the sanction allows to differentiate traffickers from retailers as in the Anti-Drug Act: $x=1$ for retailers and $x=x_{i} \geq 1$ for traffickers. The unitary sanction $s$ characterizes the penalties severity. Thus, traffickers' law enforcement costs are different from retailers' ones, because the latter make a more important number of transactions, but they pay a smaller sanction than traffickers when they are arrested. We assume that drugs sellers receive the total receipts of the trade even if they are arrested. ${ }^{6}$

Under these assumptions, we write a trafficker's expected profit (respectively a retailer's one), when law enforcement agents only pursue traffickers (respectively retailers):

$$
\pi_{j}^{T}\left(x_{j}\right)=w x_{j}-s x_{i}\left[1-(1-q)^{x_{i j}}\right]
$$

and

$$
\pi_{i}^{R}\left(x_{i}\right)=(p-w) x_{i}-s\left[1-(1-q)^{x_{i}}\right],
$$

with $w$ the wholesale price. By taking the law enforcement costs into account, traffickers and retailers seek to maximize their expected profit and they face the following trade-off: increasing quantities sold in order to increase the

\footnotetext{
${ }^{5}$ For a typical seller, who works two days a week and makes about 1,000 transactions per year, the probability of arrest at the time of a transaction $q$ is between 0.02 and 0.03 percent (Reuter, 1997).

${ }^{6}$ See Poret (2002) for a formal proof of this point.
} 
deterministic part of their profit or decreasing the number of transactions in order to reduce the risk of arrest or the amount of the sanction.

We model the drug market as a three-stage game. At the first stage, the $m$ traffickers sell to some retailers a quantity of units of drug at the wholesale price $w$. At the second stage, the $n$ retailers sell to consumers at the retail price $p$. At stage 3, each consumer purchases one unit of drug. The equilibrium concept is symmetric subgame-perfect Nash equilibrium in pure strategies.

We study two different law enforcement regimes. In the retailer-oriented regime, the authority only pursues retailers, whereas it only pursues traffickers under the trafficker-oriented regime.

\subsection{Equilibria under the two regimes}

For the complete proof of the following results, see Poret (2002). We first consider the policy where the law enforcement concerns only the retailers. The profit of the trafficker $j$ is then $\pi_{j}^{T}\left(x_{j}\right)=w x_{j}$.

Under the two conditions

$$
s \leq \frac{2}{[\ln (1-q)]^{2}}=s_{R 1}^{\max }
$$

and

$$
s \leq \frac{v}{-\ln (1-q)}=s_{R 2}^{\max },
$$

which guarantee the market existence, there exists a unique symmetric subgameperfect Nash equilibrium, $x^{*}$, implicit solution of:

$$
v-\frac{(n+1)(m+1)}{n m} x^{*}=-s(1-q)^{\frac{x^{*}}{n}} \ln (1-q)\left[1+\frac{x^{*}}{n m} \ln (1-q)\right] .
$$

The expected profit of retailer $i$ and the one of the trafficker $j$ are:

$\pi_{i}^{R *}\left(x^{*}\right)=\left(\frac{x^{*}}{n}\right)^{2}-s\left[1-(1-q)^{\frac{x^{*}}{n}}\left(1-\frac{x^{*}}{n} \ln (1-q)\right)\right]>0$ and $\pi_{j}^{T *}\left(x^{*}\right)=\frac{1}{n}\left(\frac{x^{*}}{m}\right)^{2}\left[n+1-s[\ln (1-q)]^{2}(1-q)^{\frac{x^{*}}{n}}\right]>0$ because of the condition (1).

In the trafficker-oriented law enforcement policy, retailers do not incur risk of arrest and each of them maximizes his profit $\pi_{i}^{R}(x)=\left(v-\sum_{s=1}^{n} x_{s}-w\right) x_{i}$. 
Let the following condition, which guarantees the market existence,

$$
s \leq \frac{n v}{m^{2}\left(1-(1-q)^{\frac{n}{m}}\right)+n(m-1) \ln (1-q)(1-q)^{\frac{n}{m}}}=s_{T}^{\max } .
$$

If the condition (4) is satisfied, there exists a unique symmetric subgameperfect Nash equilibrium:

$$
\bar{x}=\frac{n m}{(n+1)(m+1)}\left[v-\frac{s}{n}\left[1-(1-q)^{\frac{n}{m}}\left(1+\frac{n(m-1)}{m} \ln (1-q)\right)\right]\right] .
$$

The expected profit of retailer $i$ is $\bar{\pi}_{i}^{R}(\bar{x})=\left(\frac{\bar{x}}{n}\right)^{2}>0$.

The one of trafficker $j$ is

$\bar{\pi}_{j}^{T}(\bar{x})=\frac{n+1}{n}\left(\frac{\bar{x}}{m}\right)^{2}-s \frac{\bar{x}}{n}\left[\frac{m-1}{m}-(1-q)^{\frac{n}{m}}+\frac{1}{m}(1-q)^{\frac{n}{m}}\left(1+\frac{n(m-1)}{m} \ln (1-q)\right)\right]$. $\bar{\pi}_{j}^{T}(\bar{x}) \geq 0$ because of the condition (4).

\section{The social cost related to illicit drugs}

The illicit drugs market imposes high costs on society, as does anti-drug law enforcement, but define a policy based on minimizing drug social cost is not easy. Essential questions appear within this framework. How one measures a harm? What harm does one take into account? Does one have to consider the net harm, i.e. the harm minus the benefit, or, on the contrary, the total harm?

We define the goal of the anti-drug policy as the minimization of the drugrelated net social cost. We thus present in a first sub-section the difference between this policy and the use reduction goal. Then, we detail the harms related to drug, in terms of crime and health, in order to emphasize the methodological difficulties. Lastly, we propose a formalization of the net social cost related to illicit drugs.

\subsection{Harm reduction versus use reduction}

The principal goal of drug policy in numerous countries has been and is the use reduction. It appears like a clear target and without ambiguity. However, the terms use or consumption include different concepts. In terms of setting 
up of policy, wanting a society with many occasional consumers and few drug addicts or wanting a society with very few consumers on the whole, but tolerating some users buying great quantities of narcotics, are very different objectives. Thus, the measuring criterion of use is a parameter important to determine. Caulkins and Reuter (1997) present three concepts of use that could be targeted for reduction. First, the authorities can want to decrease the prevalence, that is, the number of consumers defined within a certain period. Within this framework, the policy can be directed towards a certain type of consumers - occasional, regular, dependent - and/or towards some products. Second, a feasible objective is the minimization of the consumed quantities. It is then important to distinguish the product and its quality or its power. Lastly, the drug users' expenditures represent another measurement of the consumption.

Harm and use do not necessarily have a direct link. A reduction in the use does not systematically lead to a fall of the caused damage and can appear while at the same time the harm related to consumption increases. Caulkins and Reuter (1997) give an example of that situation. In the United States in the 1980s, whereas the number of people reporting use of cocaine was in constant reduction, emergency room mentions of cocaine did not cease growing. In parallel, a reduction of some harms is not inevitably combined with a decrease in consumption. The needle and syringe exchange programs reduce risks related to the drug use per injection, but do not have any direct impact on the consumed quantities or the number of users.

This analysis shows that the drug problem is indirectly related to the use. The principle of reduction of harm related to use, but also trade and control of illicit drugs fits this idea.

\section{$3.2 \quad$ Illicit drugs related harms}

To model the social cost, we must define a social harm associated with the distribution and consumption of illicit drugs. This raises the question of how to evaluate the total harm caused by illicit drugs. Conceptually, there are various ways of defining harm related to drug. Firstly, according to Caulkins (1996), the sum of the harms can be expressed in two different ways. On the one hand, the total harm can be expressed by the sum of the damage undergone by each individual. It is, however, difficult to incorporate individual preferences to determine social preferences. On the other hand, the total harm represents the sum of the different types of harms caused by 
use, production, distribution, and control of illicit drugs.

We distinguish two main social harms related to illicit drugs, health and crime, which characterize the difference of approach between Europe and the United States. As mentioned by Reuter (1997), Europeans generally see illicit drugs as primarily a health problem, while Americans see them as a crime problem.

In our model, each consumer buys one unit of drug. ${ }^{7}$ Thus, the unique relevant variable to define the social harm is the quantity or number of consumers, $x$. Thus, we define a reduced form of the social harm by $H(x)$, continuous function, with $H(0)=0$. In the actual repressive regime, the main harms associated with drug use and traffic are crime and morbidity. For our analysis, we thus assume that the function $H(x)$ includes crime and health externalities related to illicit drugs, respectively $H_{C}(x)$ and $H_{H}(x)$. An increase in the quantity has several opposite effects on the social harm.

It is legitimate to suppose that the damage in terms of health increases with the consumption, even if some problems of public health do not depend on it, but on the mode of consumption, hygiene, way of life. Nevertheless, the consumers discouraged by an increase of drugs prices are, in first, the individuals having a weak propensity to pay for drug, that is, the no-addicts. The consumers more easily ready to stop their consumption following a rise in price are thus the ones creating a weak health damage. Moreover, when retail price increases, the more addicted users devote a greater part of their resources to purchasing drugs. They might fail to get the essential goods (food, housing) and then their health may deteriorate. More, higher prices are likely to lead addicted users to more efficient, and frequently dangerous, modes of drug-taking (Caulkins and Reuter, 1996). But, in our model, we can not distinguish light or heavy users. Finally, we suppose that the function of marginal health harm is positive, $H_{H}^{\prime}(x)>0$.

For crime and violence damage, Resignato (2000) distinguishes three types of violence which help to explain a causal relation between illicit drug use and violent crime. The first form of violence is the psychopharmacological effects of the products themselves. For this argument, a distinction between the different products and a parallel with legal drugs as alcohol are necessary. ${ }^{8}$

\footnotetext{
${ }^{7}$ The fact of not being able to distinguish occasional consumers from addicts is a limit of this model, because the health harm and crime harm are very different according to the consumed quantity and frequency.

${ }^{8}$ Resignato (2000) quotes several studies which indicate that marijuana plays no causal
} 
The second violence related to drug is due to the economic constraint which lies heavy on users, called economic compulsive violence. Even when the price increases, addicted users continue to consume drug. Among these consumers, some make offences to finance their practice. Resignato (2000) estimates that results of research on economic compulsive violence are lukewarm. The principal difficulty is to establish the link between the criminal act due to an economic constraint and the need for drugs. It may not be clear which is the cause, which is the effect. This may be the result of a self-selection process: illicit drugs users already transgress the law by that activity, they thus are willing to break the law in committing crimes. ${ }^{9}$

The third type of violence is the systemic violence. It is an intrinsic characteristic of illegal markets, because property rights are not protected by authorities and contracts can not be enforced. Moreover, the marginal cost of violent acts is likely to be smaller in an illegal market than in a legal one, because people are already in the illegality and no legal and judicial actions are possible (Miron and Zwiebel, 1995). Thus, turf wars, assaults and homicides committed within dealing hierarchies, robberies of drugs sellers and buyers, elimination of informers, punishments for selling adulterated products, punishments for failing to pay one's debts are a common occurrence.

Finally, the empirical results of Resignato (2000) indicate that the relationship between psychopharmacological/economic compulsive effects and violent crime may be weak and that drug-related crime is more likely the result of the systemic side. ${ }^{10}$ Moreover, Miron and Zwiebel (1995) suggest that violence is likely to increase with higher prices. When drugs prices increase, buyers are less numerous but they represent more attractive victims for thieves. Furthermore, a decrease in the number of consumers may exacerbate turf wars, competition between sellers being stronger. From these arguments, we assume that the harm in terms of criminality is decreasing in the quantity, $H_{C}^{\prime}(x)<0$.

Further costs may result from drug prohibition and law enforcement,

role in violent crime.

${ }^{9}$ Moreover, many studies as the one of Breteville-Jensen and Biørn (2001) refute the claim that addicts maintain a price inelastic demand. This partly challenges the economic compulsion model.

${ }^{10} \mathrm{~A}$ study of Goldstein, Brownstein and Ryan (1992) estimated that 14 percent of the 53 percent of homicides related to drug selling or use were classified as psychopharmacological and 74 percent as due to drug trade. 
such as the bad quality of products, the potential loss of civil liberties, the corruption, the money laundering, and the prison overpopulation, but it is difficult to link these indirect costs to the total level of drug use.

Thus, we define the social harm as the sum of the health harm and the crime harm, $H(x)=H_{H}(x)+H_{C}(x)$. The marginal harm is thus equal to $H^{\prime}(x)=H_{H}^{\prime}(x)+H_{C}^{\prime}(x)$, with $H_{H}^{\prime}(x)>0$ and $H_{C}^{\prime}(x)<0$.

The harm is increasing in quantity, $H^{\prime}(x)>0$, when $H_{H}^{\prime}(x)>\left|H_{C}^{\prime}(x)\right|$, that is, when, at the margin, health is the most important harm. Marginal harm is negative, when $H_{H}^{\prime}(x)<\left|H_{C}^{\prime}(x)\right|$, that is, when the marginal crime harm, in absolute value, is higher than the marginal health harm. Thus, we will distinguish two cases: $H^{\prime}(x)>0$ and $H^{\prime}(x)<0$.

\subsection{The net social cost}

A crucial question related to the analysis of the drug-related social cost is to consider the social harm net of benefits received by persons implicated in this illegal trade or the total social harm (with the net cost of law enforcement only). In the economic theory of law enforcement (see Polinsky and Shavell (2000)), the social welfare is defined as the gains individuals obtain from committing their acts, less the harms caused, and less the net costs of law enforcement. As mentioned by Miron and Zwiebel (1995), the utility of drug consumption is ignored in public discourse on drug policy, but the extent to which users have pursued drugs, despite severe penalties and high prices, suggests they derive a substantial utility of these products consumption. In a non-paternalistic government intervention perspective, and thus, if one regards drugs users as rational agents who derive some satisfaction from consuming psychotropic products, the users' surplus has to be deducted from harms related to illicit drugs.

This question is thornier regarding sellers' profits. It might seem shocking to take into account the traffickers' profits in the social welfare, but profits of the production and sale of illicit drugs represent non-negligible resources for many people, in producer and consumer countries. In other words, even if we study an illegal market, the income of this activity contributes to the legal economy and to the wealth of numerous countries and it is necessary to take it into account. Moreover, this approach is justified by the fact that the negative externalities related to drugs, mainly in terms of violence and health, are taken into account in a damage caused by illegal narcotics. Costs, but also benefits, related to drug have to be included in a utilitarian analysis 
of the illicit drug problem.

We seek the optimal law enforcement policy according to the identity of the pursued sellers (i.e. retailers or traffickers) with the objective of reducing the social cost related to illicit drug consumption, trade and control. We assume that the unique law enforcement instrument set by law enforcement authorities is the sanction. The latter do not set resources allocated to the law enforcement: these resources are related to a state budgetary constraint. We assume too that the levied sanction is a fine. The introduction of the imprisonment into this model should not qualitatively change the results. As the imprisonment generates additional costs for society and drugs sellers and as the fine is costless, the optimal sanction is the fine (see Garoupa, 1997).

The enforcement authority's goal is to minimize the net social cost, $C(s)$, associated with drugs by setting the unitary fine, $s$, the resources allocated to law enforcement being fixed to $D$. It includes the social harm associated with the distribution and consumption of drugs, the net cost of the law enforcement, equal to the resources allocated to the law enforcement $D$ minus the expected amount of the fine collected by the enforcement authority $S(x(s), s)$, and the agents' surplus, consumers' surplus and sellers' profits. The net social cost is then:

$$
\begin{aligned}
C(s)= & H(x(s))+D-S(x(s), s) \\
& -\frac{x(s)^{2}}{2}-n \pi_{i}^{R}(x(s), s)-m \pi_{j}^{T}(x(s), s)
\end{aligned}
$$

with $x(s)=x^{*}(s)$ in the retailer-oriented regime and $x(s)=\bar{x}(s)$ in the trafficker-oriented regime. We note respectively $C^{*}(s)$ and $\bar{C}(s)$ the net social cost under the retailer-oriented regime and under the trafficker-oriented regime.

Whatever the law enforcement regime, the development of the net social cost gives:

$$
C(s)=H(x(s))+D-\frac{x(s)(2 v-x(s))}{2}
$$

The equation (6) shows that the social cost depends on the unit fine only through the total quantity of drugs consumed, because the fine is a monetary transfer between sellers pursued and the government.

The first derivative of the social cost related to illicit drugs is thus written:

$$
\frac{d C(s)}{d s}=\frac{d x(s)}{d s}\left[H^{\prime}(x(s))-(v-x(s))\right]
$$


The condition $H^{\prime \prime}(x)>-1$ is necessary for the second order condition. We assume to simplify the analysis that the harm is convex $\left(H^{\prime \prime}(x)>0\right)$.

We can notice that the marginal cost depends on three terms:

(i). the sensitivity of the quantity to the unit fine $\left(\frac{d x(s)}{d s}\right)$

(ii). the link between the consumed quantity and the social harm $\left(H^{\prime}(x(s))\right)$, which translates the main cause of harm between health and crime.

(iii). the effect of the consumed quantity on the net surplus of the drugs consumers and sellers, which is always positive $((v-x(s)) \geq 0)$.

\section{Results and comparison}

We present results in this section by studying the model according to the law enforcement system imposed by the authorities.

\subsection{The retailer-oriented regime}

In the retailer-oriented law enforcement regime, the program of the authorities is the following:

$$
\min _{s}\left\{C^{*}(s)=H\left(x^{*}(s)\right)+D-\frac{x^{*}(s)\left(2 v-x^{*}(s)\right)}{2}\right\}
$$

with $x^{*}(s)$ defined by the equation (3).

Before studying results of the program (8), we study the sensitivity of the equilibrium quantity to the unit fine.

Lemma 1. There exists a threshold of the probability of arrest at the time of a transaction, $\widetilde{q}=1-e^{-\frac{(n+1)(m+1)}{v}}$, such that

$$
\left\{\begin{array}{l}
\frac{d x^{*}(s)}{d s}<0 \quad \text { if } \quad q<\widetilde{q} \\
\frac{d x^{*}(s)}{d s} \geq 0 \quad \text { if } \quad q \geq \widetilde{q}
\end{array}\right.
$$

Proof. See Appendix A. 
This result is due to the fact that we introduce concave law enforcement costs in addition to the vertical relationship between traffickers and retailers. An increase of the unit fine has two opposite effects which explain the total effect of a tougher law enforcement policy on the equilibrium demand. ${ }^{11}$ The first one is the positive "double marginalization" effect, characterized by

$$
\frac{\partial w^{*}(s)}{\partial s}=\frac{\ln (1-q)}{m+1}(1-q)^{\frac{x *}{n}}\left(1-\frac{x^{*}}{n} \ln (1-q)\right)<0 .
$$

As usual in the analysis of vertical relationships between producers and retailers, if retailers' costs increase, producers diminish the wholesale price in order to partially offset the decrease of demand. The second effect is the negative "transaction costs" effect. As their law enforcement costs increase, retailers decrease their supply in order to lower the number of transactions. According to the initial level of the probability of arrest at the time of a transaction, the positive or negative effect may dominate.

When the probability of arrest is low $(q<\widetilde{q})$, an increase in the unit sanction induces a decrease of quantity: the "transaction costs" effect is dominant. The probability of arrest at the time of a transaction is initially low, thus each transaction is not very costly. Then, the drug supply is high. But, finally, retailers face high law enforcement costs $\left(s\left[1-(1-q)^{x_{i}}\right]\right)$ because of the number of transactions. An increase of the unitary fine raises these costs. To avoid this, retailers lower their supply. On the opposite, when the probability of arrest is high $(q \geq \widetilde{q})$, an increase of the unitary sanction induces a rise of the number of consumers: the "double marginalization" effect is dominant. The probability of arrest is initially high and each transaction is costly. Therefore, the drug supply is low and retailers face low law enforcement costs. An increase in the unitary sanction has only a weak effect on these costs. But, the double marginalization mechanism appears: traffickers decrease the wholesale price. Then, the retailers increase their supply.

Let us now determine the optimal unit fine.

Proposition 1. In the retailer-oriented law enforcement regime, the optimal unitary fine, $s^{*}$, set by the authorities in order to minimize the drug-related net social cost depends on the marginal harm, $H^{\prime}\left(x^{*}\right)$, and on the sensitivity

\footnotetext{
${ }^{11}$ To illustrate the threshold probability of arrest, we consider the following example: $v=500,000, m=2$, and $n=30$. In that case, $\widetilde{q}=0.018$ percent.
} 
of the equilibrium quantity to the unitary fine, $\frac{d x^{*}(s)}{d s}$, that is, on the level of the probability of detection at the time of a transaction, $q$.

(i). When $H^{\prime}(0)>v, s^{*}$ depends on $q$.

- If $q<\widetilde{q}$, then the optimal unit fine is the maximum one, with

$-s^{*}=s_{R 2}^{\max }$ if $q \leq q^{s}=1-e^{-2 / v}$

$-s^{*}=s_{R 1}^{\max }$ if $q^{s}<q<\widetilde{q}$

- If $q>\widetilde{q}$, then the optimal unit fine is the minimum one, $s^{*}=0$.

(ii). When $H^{\prime}\left(x^{*}\right)>0$ and $H^{\prime}(0)<v, s^{*}$ is the interior optimum implicitly defined by:

$$
H^{\prime}\left(x^{*}\left(s^{*}\right)\right)=v-x^{*}\left(s^{*}\right) .
$$

(iii). When $H^{\prime}\left(x^{*}\right)<0, s^{*}$ depends on $q$.

- If $q<\widetilde{q}$, then the optimal unit fine is the minimum one, $s^{*}=0$.

- If $q>\widetilde{q}$, then the optimal unit fine is the maximum one, $s^{*}=s_{R 1}^{\max }$.

Proof. See Appendix B.

These results are explained by the sensibility of the equilibrium quantity to the unit fine (Lemma 1) and two effects of the unit fine on the net social cost through the quantity (see Equation (7)).

When the number of potential consumers is low in respect to the level of the marginal harm in zero $\left(H^{\prime}(0)>v\right)$, the social harm effect is dominant. The objective of reducing the social cost amounts to an objective of reducing the total quantity of drugs consumed. When the main effect of drugs on the society is a health problem and when the damage caused by drugs is high from the lower quantity of drug consumed, it is necessary to reduce the consumption. This reduction is obtained by a maximal fine when the quantity is decreasing in the unit fine and by the minimum one in the opposite case.

When the marginal health harm is higher than the marginal crime harm $\left(H^{\prime}\left(x^{*}\right)>0\right)$ and when $H^{\prime}(0)<v$, the two effects conflict. A fall in quantity consumed is positive in terms of reduction of the health harm, and thus makes it possible to reduce the net social cost. This effect is the expected result of anti-drug law enforcement policies. But, this fall in quantity decreases the net surplus of the drug market agents and increases the net social cost. The authorities face a trade-off between these effects. Therefore, whatever the 
sensitivity of the quantity to the unitary fine, they have to set the fine at a level such as the two opposite effects compensate. Moreover, the optimal interior unitary fine is such as the marginal harm is equal to the equilibrium price.

When the marginal crime harm is higher than the marginal health harm (in absolute value), effects of the quantity on the agents' surplus and on the harm go in the same direction: the net social cost is a decreasing function of quantities. Consumed quantities have to be high enough to reduce the net social cost, because harms related to illicit drugs are due to the high prices of these products. Thus paradoxically, the aim of a cost-reducing policy is to raise the consumption. In this case, no trade-off appears between the two effects described before; the solution of the minimization program of the net social cost is a corner solution. It depends on the sensitivity of the quantity to the unit fine. If the probability of detection at the time of a transaction is weak $(q<\widetilde{q})$, the quantity is decreasing with the unit fine. Therefore, in order to minimize the net social cost, it is necessary to set the unit fine at its minimum level. This result suggests that the optimal policy is the depenalization of drugs, the amount of the resources allocated to law enforcement $D$ being then saved. If the probability of detection is relatively high $(q>\widetilde{q})$, exchanged quantities are increasing with the unit fine. The net social cost reaches its minimum when the unitary fine is on its maximum level $s_{R}^{\max }$. To increase drugs quantities, drug law enforcement policy has to be very tough.

It is interesting to note that these last results are in contradiction with the usual results in economics of law enforcement. Indeed, in usual cases ${ }^{12}$ the two instruments of law enforcement, probability of detection and sanction, are substitutes. However, in our model, they can be substitutes or complements. When the main cause of harm is crime, if the probability of detection is high, the optimal unitary sanction has to be on its maximum level. And in a symmetrical way, when probability of arrest is low, the optimal fine must be equal to zero. This apparently paradoxical result comes from the objective of the law enforcement policy. It is not a question any more of deterring the drug trade, that is, reducing market quantities, but of minimizing the net social cost related to illicit drugs. Indeed, Lemma 1 brings to the fore that, in order to reduce the illicit drug quantity, the two instruments are substitutes: if the probability of arrest is low, the sanction must be high and

\footnotetext{
${ }^{12}$ See Becker (1968).
} 
vice-versa. When the harm is such that the reduction of social cost related to drugs is equivalent to the maximization of the drug trade $\left(H^{\prime}\left(x^{*}\right)<0\right)$, the instruments are complements.

\subsection{The trafficker-oriented regime}

When the law enforcement system is oriented towards the traffickers, the program of the authorities is:

$$
\min _{s}\left\{\bar{C}(s)=D+H(\bar{x}(s))-\frac{\bar{x}(2 v-\bar{x}(s))}{2}\right\}
$$

with $\bar{x}(s)$ defined by the equation (5).

The social cost depends on the unit fine through the total quantity of drug consumed. The sensitivity of the quantity to the unit sanction in a law enforcement policy oriented against the traffickers is studied in the following lemma.

Lemma 2. Whatever the law enforcement level, illicit drugs quantities are decreasing in the unit fine.

Proof. By differentiating (5), we obtain:

$\frac{d \bar{x}(s)}{d s}=\frac{-m}{(n+1)(m+1)}\left[1-(1-q)^{\frac{n}{m}}\left(1+\frac{n(m-1)}{m} \ln (1-q)\right)\right]<0$.

When the unit fine increases, traffickers' expected law enforcement costs become higher, then each one reduces the quantity he/she sells retailers and the market quantity diminishes. Under the trafficker-oriented law enforcement regime, the traffickers bear the "transaction costs" effect, but the balance of power is in their favor because of their Stackelberg leadership. Consequently, when the law enforcement policy is tougher, they reduce quantities they sell retailers in order to reduce their costs. The "double marginalization" effect studied in the retailer-oriented regime does not appear in this case.

Proposition 2. In the trafficker-oriented law enforcement regime, the optimal unitary fine, $\bar{s}$, set by the authorities in order to minimize the net social cost related to illicit drugs only depends on the marginal harm, $H^{\prime}(\bar{x})$.

(i). When $H^{\prime}(0)>v$, the optimal unitary fine is the maximum one $\bar{s}=$ $s_{T}^{m a x}=\frac{n v}{m^{2}\left(1-(1-q)^{\frac{n}{m}}\right)+n(m-1) \ln (1-q)(1-q)^{\frac{n}{m}}}$. 
(ii). When $H^{\prime}(\bar{x})>0$ and $H^{\prime}(0)<v$, the optimal unitary fine $\bar{s}$ is an interior optimum, implicitly defined by:

$$
H^{\prime}(\bar{x}(\bar{s}))=v-\bar{x}(\bar{s})
$$

(iii). When $H^{\prime}(\bar{x})<0$, the optimal unitary fine is the minimum one $\bar{s}=0$.

Proof. See Appendix C.

The effects discussed above for the general case explain as well the results in the trafficker-oriented policy.

When the positive marginal social harm is very high $\left(H^{\prime}(0)>v\right)$, the authorities want to reduce the drug consumption. Since the equilibrium quantity is decreasing in the unit fine, the optimal sanction is the maximal unit fine.

When the drug-related social harm is increasing in quantities, that is, when the marginal health harm is higher, in absolute value, than the marginal criminal harm, and when $H^{\prime}(0)<v$, we find again the two opposite effects described in the retailer-oriented regime: the negative effect of the quantity on the harm and the positive effect on the net surplus of consumers and sellers. As in the case of a law enforcement policy directed towards the retailers, the authorities face a trade-off between these effects. In the same way, the authorities have to set the fine at a level such as the two opposite effects compensate.

When the most important harm is the one related to crime, the effects of the quantity on the net social cost go in the same direction: the social cost is an increasing function of $\bar{x}$. However, when the authorities direct law enforcement towards the traffickers, quantities are always decreasing with the unit fine; there is no threshold effect. With the objective of minimization of the net social cost, the unitary fine must be fixed at its minimum level. Within a law enforcement system directed towards traffickers and when the social harm is decreasing in the market quantity, depenalization is then the optimal policy.

\subsection{Comparison of the two law enforcement regimes}

In the following tables (Table 1 and Table 2), we summarize the results of the model within the framework of the two law enforcement systems. 
Table 1: Retailer-oriented law enforcement regime

\begin{tabular}{c||c|c|c}
$s^{*}$ & $H^{\prime}(0)>v$ & $H^{\prime}\left(x^{*}\right)>0$ and $H^{\prime}(0)<v$ & $H^{\prime}\left(x^{*}\right)<0$ \\
\hline \hline $\begin{array}{c}q<\widetilde{q} \\
\left(\frac{d x^{*}(s)}{d s}<0\right)\end{array}$ & $s^{*}=\left\{\begin{array}{c}s_{R 2}^{\max } \text { if } q \leq q^{s} \\
s_{R 1}^{\max } \text { if } q^{s}<q\end{array}\right.$ & $H^{\prime}\left(x^{*}\left(s^{*}\right)\right)=v-x^{*}\left(s^{*}\right)$ & $s^{*}=0$ \\
\hline $\begin{array}{c}q>\widetilde{q} \\
\left(\frac{d x^{*}(s)}{d s}>0\right)\end{array}$ & $s^{*}=0$ & $H^{\prime}\left(x^{*}\left(s^{*}\right)\right)=v-x^{*}\left(s^{*}\right)$ & \\
\hline \hline & & $s^{*}=s_{R 1}^{\max }$ \\
$\begin{array}{c}\text { equivalent } \\
\text { objective } \\
\text { in } x^{*}\end{array}$ & $\min x^{*}$ & $x^{*}$ interior solution & $\max x^{*}$ \\
\hline
\end{tabular}

Table 2: Trafficker-oriented law enforcement regime

\begin{tabular}{c||c|c|c}
$\bar{s}$ & $H^{\prime}(0)>v$ & $H^{\prime}(\bar{x})>0$ and $H^{\prime}(0)<v$ & $H^{\prime}(\bar{x})<0$ \\
\hline \hline$\forall q \frac{d \bar{x}(s)}{d s}<0$ & $\bar{s}=s_{T}^{\max }$ & $\bar{s}: H^{\prime}(\bar{x}(\bar{s}))=v-\bar{x}(\bar{s})$ & $\bar{s}=0$ \\
\hline \hline $\begin{array}{c}\text { equivalent } \\
\text { objective in } \bar{x}\end{array}$ & $\min \bar{x}$ & $\bar{x}$ interior solution & $\max \bar{x}$
\end{tabular}


As usual in the law enforcement literature, we find that the optimal sanction is not necessarily maximal. We show as well that, under the two law enforcement systems, under certain conditions, it is optimal to set up a depenalization of the drug market.

By comparing the two law enforcement systems, it appears that, to set up an optimal law enforcement policy, it is not necessary to know the value of the probability of arrest at the time of a transaction and the threshold $\widetilde{q}$ when the law enforcement agents pursue traffickers. Thus, in a trafficker-oriented law enforcement regime, the authorities do not need to know the technology of detection, that is, the link between the resources allocated to detection, $D$, and the probability of arrest, $q$. In the framework of a law enforcement policy, it is always difficult to know the technology and effectiveness of the means of detection. In our model, a trafficker-oriented law enforcement policy thus represents the advantage of not requiring the knowledge of this information.

In terms of social cost, we can notice that

- $C^{*}(0)=\bar{C}(0)=H\left(\frac{n m v}{(n+1)(m+1)}\right)-\frac{n m[m n+2 m+2 n+2]}{2(n+1)^{2}(m+1)^{2}} v^{2} ;$

- $C^{*}\left(s_{R 1}^{\max }\right)=C^{*}\left(s_{R 2}^{\max }\right)=\bar{C}\left(s_{T}^{\max }\right)=D$;

- $C^{*}\left(s^{*}\right)=\bar{C}(\bar{s})$ because social cost depends on the unit fine only through $x$ and $x^{*}\left(s^{*}\right)=\arg \min _{x} C(x(s))=\bar{x}(\bar{s})$.

It is not possible to state whether social cost is lower under depenalization than "tolerance zero" policy without specifying functional forms for the social harm and for the detection technology to link the resources allocated to detection $D$ and the probability of arrest at the time of a transaction $q$. Here we can make some comments on the social cost in assuming three functional forms for the social harm corresponding to the three conditions on the marginal social harm. 
Example 1: $H(x)=\alpha v x+\frac{x^{2}}{2}$, with $\alpha>1, H^{\prime}(x)=\alpha v+x>0$ and $H^{\prime}(0)=\alpha v>v$.

$\bar{C}\left(s_{T}^{\max }\right)=D(q)$. As the detection is costly, it is better to set up a low level of detection ressources.

Example 2: $H(x)=x^{2}$, with $H^{\prime}(x)=2 x>0$ and $H^{\prime}(0)<v$. $\bar{C}(\bar{s})=-6 v+D(q)<D(q)$.

Example 3: $H(x)=1 / x$, with $H^{\prime}(x)=-1 / x^{2}<0$.

$\bar{C}(0)=\frac{(n+1)(m+1)}{n m v}-\frac{n m[m n+2 m+2 n+2]}{2(n+1)^{2}(m+1)^{2}} v^{2}$, which can be negative when the number of potential consumers is high.

\section{Conclusion}

This paper presents a normative approach of the anti-drug policy. We propose an analysis of an optimal law enforcement based on the reduction of the net social cost related to illicit drugs. The results highlight necessary precautions before setting up a such policy. Indeed, the optimal unit fine depends on several parameters: the sellers pursued by the authorities, the probability of arrest and conviction at the time of a transaction, which is a function of resources allocated to detection and technology of detection, and effect of market quantities on the drug-related social harm.

As a consequence, before any public intervention, in order to set an efficient anti-drug policy reducing drugs harms, quantitative studies of the social harm related to illicit drugs are necessary. It is essential to evaluate the different externalities related to illicit drugs, in particular, the ones related to the products as psychotropic and the ones due to prohibition and law enforcement, and the relation between the drug trade and the different damages related to drugs.

In the debate about the drug problem, an other question is the legalization of drugs or only of milder drugs. Few theoretical works are interested in this topic, see nevertheless Clark (2003) who studies the potential impact of drug legalization on social welfare and Becker, Murphy and Grossman (2004), who compare outputs and prices when a good is legal and taxed with outputs and prices when it is illegal. The evaluation of the different harms related to drugs in distinguishing the ones related to the policy from the ones related to the 
products is crucial as well in this issue.

\section{A Proof of Lemma 1}

At equilibrium, $x^{*}(s)$ is defined by the equation (3), that is, $\phi\left(x^{*}\right)=0$ with $\phi(x)=v-\frac{(n+1)(m+1)}{n m} x+s(1-q)^{\frac{x}{n}} \ln (1-q)\left[1+\frac{x}{n m} \ln (1-q)\right]$.

By differentiating $\phi\left(x^{*}\right)=0$, we obtain

$\frac{d x^{*}(s)}{d s}=\frac{(1-q)^{\frac{x^{*}(s)}{n}} \ln (1-q)\left[1+\frac{x^{*}(s)}{n m} \ln (1-q)\right]}{\frac{(n+1)(m+1)}{n m}-\frac{s}{n}[\ln (1-q)]^{2}(1-q)^{\frac{s^{*}}{n}}\left[\frac{m+1}{m}+\frac{x^{*}(s)}{n m} \ln (1-q)\right]}$.

As $\frac{(n+1)(m+1)}{n m}-\frac{s}{n}[\ln (1-q)]^{2}(1-q)^{\frac{s^{*}}{n}}\left[\frac{m+1}{m}+\frac{x^{*}(s)}{n m} \ln (1-q)\right]>0$ thanks to the condition (1), $\frac{d x^{*}(s)}{d s}>0$ if $1+\frac{x^{*}(s)}{n m} \ln (1-q)<0$.

Let $\widetilde{q}$ defined by $1+\frac{x^{*}(s)}{n m} \ln (1-\widetilde{q})=0$, but $\phi\left(x^{*}\right)=0$, thus $\phi\left(-\frac{n m}{\ln (1-\widetilde{q})}\right)=0$, i.e., $\widetilde{q}=1-e^{-\frac{(n+1)(m+1)}{v}}$.

Finally, $\frac{d x^{*}(s)}{d s}<0$ if $q<\widetilde{q}$ and $\frac{d x^{*}(s)}{d s} \geq 0$ if $q \geq \widetilde{q}$.

\section{B Proof of proposition 1}

As $C^{*}(s)$ depends on $s$ only through $x^{*}(s)$, we can decompose $\frac{d C^{*}(s)}{d s}$ :

$$
\frac{d C^{*}(s)}{d s}=\frac{d C\left(x^{*}(s)\right)}{d x^{*}(s)} \frac{d x^{*}(s)}{d s},
$$

with

$$
\frac{d C\left(x^{*}(s)\right)}{d x^{*}(s)}=C^{\prime}\left(x^{*}(s)\right)=H^{\prime}\left(x^{*}(s)\right)-\left(v-x^{*}(s)\right) .
$$

Let us study the function $C^{\prime}\left(x^{*}(s)\right)$. $C^{\prime}\left(x^{*}(s)\right)$ is increasing in $x^{*}(s)$ since $C^{\prime \prime}\left(x^{*}(s)\right)=H^{\prime \prime}\left(x^{*}(s)\right)+1>0$.

(i). If $H^{\prime}(0)>v^{13}$, then $C^{\prime}\left(x^{*}(s)\right)>0 \forall x^{*}(s)$. In that case,

\footnotetext{
${ }^{13} \mathrm{As} H^{\prime \prime}(x)>0, H^{\prime}(0)>v \Rightarrow H^{\prime}(x)>0 \forall x \geq 0$.
} 
- when $q<\widetilde{q}, \frac{d x^{*}(s)}{d s}<0$ (Lemma 1) and $\frac{d C^{*}(s)}{d s}<0 \forall s$. Thus, the optimal level of the unit sanction is the maximum one: $s^{*}=$ $s^{\max }=\min \left\{\frac{2}{[\ln (1-q)]^{2}}, \frac{v}{-\ln (1-q)}\right\}$.

- When $q>\widetilde{q}, \frac{d x^{*}(s)}{d s}>0$ (Lemma 1) and $\frac{d C^{*}(s)}{d s}>0 \forall s$. Thus, the optimal level of the unit sanction is the minimum one: $s^{*}=0$. In this case, $x^{*}=\frac{n m v}{(n+1)(m+1)}$.

(ii). If $H^{\prime}\left(x^{*}(s)\right)>0$ and $H^{\prime}(0)<v$, then it exists a $x^{*}(s)$ such as $C^{\prime}\left(x^{*}(s)\right)=0$.

In this case, whatever the sensitivity of the quantity to the unit fine, that is, the sign of $\frac{d x^{*}(s)}{d s}$, the equation $\frac{d C^{*}(s)}{d s}=0$ admits a unique candidate optimum, noted $s^{*}$, defined by the following equation

$$
H^{\prime}\left(x^{*}\left(s^{*}\right)\right)=v-x^{*}\left(s^{*}\right) .
$$

The second order condition is

$$
\frac{d^{2} C^{*}(s)}{d s^{2}}=\frac{d^{2} x^{*}(s)}{d s^{2}}\left[H^{\prime}\left(x^{*}(s)\right)-\left(v-x^{*}(s)\right)\right]+\left(\frac{d x^{*}(s)}{d s}\right)^{2}\left[H^{\prime \prime}\left(x^{*}(s)\right)+1\right]
$$

and it is satisfied at the candidate optimum $s^{*}$ since $H^{\prime \prime}>0$. Thus, $s^{*}$ is a global minimum.

(iii). If $H^{\prime}\left(x^{*}(s)\right)<0$, then $C^{\prime}\left(x^{*}(s)\right)<0 \forall x^{*}(s)$. In this case,

- when $q<\widetilde{q}, \frac{d x^{*}(s)}{d s}<0$ (Lemma 1) and $\frac{d C^{*}(s)}{d s}>0 \forall s$. Thus, the optimal level of the unit sanction is the minimum one: $s^{*}=0$. In this case, $x^{*}=\frac{n m v}{(n+1)(m+1)}$.

- When $q>\widetilde{q}, \frac{d x^{*}(s)}{d s}>0$,(Lemma 1) and $\frac{d C^{*}(s)}{d s}<0 \forall s$. Thus, the optimal level of the unit sanction is the maximum one: $s^{*}=$ $s^{\max }=\min \left\{\frac{2}{[\ln (1-q)]^{2}}, \frac{v}{-\ln (1-q)}\right\}$.

\section{Proof of proposition 2}

As $\bar{C}(s)$ depends on $s$ only through $\bar{x}(s)$, we can decompose $\frac{d \bar{C}(s)}{d s}$ :

$$
\frac{d \bar{C}(s)}{d s}=\frac{d C(\bar{x}(s))}{d \bar{x}(s)} \frac{d \bar{x}(s)}{d s}
$$


with

$$
\frac{d C(\bar{x}(s))}{d \bar{x}(s)}=C^{\prime}(\bar{x}(s))=H^{\prime}(\bar{x}(s))-(v-\bar{x}(s)) .
$$

Let us study the function $C^{\prime}(\bar{x}(s)) . C^{\prime}(\bar{x}(s))$ is increasing in $\bar{x}(s)$ since $C^{\prime \prime}(\bar{x}(s))=H^{\prime \prime}(\bar{x}(s))+1>0$.

(i). If $H^{\prime}(0)>v$, then $C^{\prime}(\bar{x}(s))>0 \forall \bar{x}(s)$. As $\frac{d \bar{x}(s)}{d s}<0$ (Lemma 2), the optimal level of the unit sanction is the maximum one:

$\bar{s}=\frac{n v}{m^{2}\left(1-(1-q)^{\frac{n}{m}}\right)+n(m-1) \ln (1-q)(1-q)^{\frac{n}{m}}}$.

(ii). If $H^{\prime}(\bar{x}(s))>0$ and $H^{\prime}(0)<v$, then it exists a $\bar{x}(s)$ such as $C^{\prime}(\bar{x}(s))=0$.

In this case, the equation $\frac{d \bar{C}(s)}{d s}=0$ admits a unique candidate optimum, noted $\bar{s}$, defined by the following equation

$$
H^{\prime}(\bar{x}(\bar{s}))=v-\bar{x}(\bar{s}) .
$$

The second order condition is satisfied since $H^{\prime \prime}>0$ :

$$
\frac{d^{2} \bar{C}(s)}{d s^{2}}=\left(\frac{d \bar{x}(s)}{d s}\right)^{2}\left[H^{\prime \prime}(\bar{x}(s))+1\right]>0
$$

Thus, $s^{*}$ is a global minimum.

(iii). If $H^{\prime}(\bar{x}(s))<0$, as $\frac{d \bar{x}(s)}{d s}<0$, the function $\bar{C}(s)$ is increasing in $s$, whatever $s$. Thus, the optimal level of the unit sanction is the minimum one: $\bar{s}=0$.

\section{References}

[1] Becker G. (1968), "Crime and Punishment: An Economic Approach", Journal of Political Economy, 76, 169-217.

[2] Becker G.S., Grossman M. and K.M. Murphy (1991), "Rational addiction and the effect of price on consumption", American Economic Review, 81 (2), 237-241.

[3] Becker G.S., Grossman M. and K.M. Murphy (2004), "The Economic Theory of Illegal Goods: The Case of Drugs", NBER Working Paper Series 10976. 
[4] Breteville-Jensen A.L. and E. Biørn (2001), "Estimating Addicts Price response of Heroin: A Panel Data Approach Based on a Re-interviewed Sample", Memorandum 8/2001 Department of Economics, University of Oslo.

[5] Caulkins J.P. (1993), "Zero-Tolerance Policies: Do They Inhibit or Stimulate Illicit drug Consumption?", Management Science, 39 (4), 458-476.

[6] Caulkins J.P. (1995), "Estimating elasticities of demand for cocaine and heroin with data from the drug use forecasting system", School of Public Policy and Management Working Paper series 95-13, Carnegie Mellon University.

[7] Caulkins J.P. (1996), "What Does Mathematical Modeling Tell Us About Harm Reduction?", Drug and Alcohol Review, 15, 231-235.

[8] Caulkins J.P. and P. Reuter (1996), "The Meaning and Utility of Drug Prices", Addiction, 91 (9), 1261-1265.

[9] Caulkins J.P. and P. Reuter (1997), "Setting Goals for Drug Policy: Harm Reduction or Use Reduction?", Addiction, 92 (9), 1143-1150.

[10] Chiu S., Mansley E.C. and J. Morgan (1998), "Choosing the right battlefield for the war on drugs: an irrelevance result", Economics Letters, $59,107-111$.

[11] Clark A. (2003), "The Economics of Drug Legalization”, Mimeo DELTA.

[12] Garoupa N. (1997), "The Theory of Optimal Law Enforcement”, Journal of Economic Surveys, 11, 267-295.

[13] Goldstein P., Brownstein H., and P. Ryan (1992), "Drug-Related Homicides in New York: 1984 and 1988." Crime and Delinquency, 38(4), 459-476.

[14] Kopp P. (1997), L'économie de la drogue, La Découverte coll. Repères, Paris.

[15] Lee L.W. (1993), "Would Harassing Drug Users Work?", Journal of Political Economy, 101 (5), 939-959. 
[16] Miron A.J. and J. Zwiebel (1995), "The Economic Case Against Drug Prohibition", Journal of Economic Perspectives, 9, 175-192.

[17] Mansour A., Marceau N. and S. Mongrain (2001), "Gangs and Crime Deterrence", CREFE Working Paper No. 138, Université du Québec à Montréal.

[18] Polinsky M. and S. Shavell (2000), "The Economic Theory of Public Enforcement of Law", Journal of Economic Literature, 38 (1), 45-76.

[19] Poret S. (2002), "Paradoxical Effects of Law Enforcement Policies: The case of Illicit Drug Market", International Review of Law and Economics, $22(4), 465-493$.

[20] Poret S. and C. Téjédo (2003), "Law Enforcement and Concentration in Illicit Markets", CREST Working Paper No. 2003-02.

[21] Prinz A. (1997), "Drugs: Do European drugs policies matter?", Economic Policy, 12, 371-385.

[22] Resignato A.J. (2000), "Violent Crime: A Function of Drug Use or Drug Enforcement?", Applied Economics, 32, 681-688.

[23] Reuter P. and R. Mac Coun (1996), "Harm reduction and social policy: should addicts be paid?", Drug and Alcohol Review, 15, 225-230.

[24] Reuter P. (1997), "Why Can't We Make Prohibition Work Better?", Proceedings of the American Philosophical Society, 141, 262-275.

[25] Rottenberg S. (1968), "The clandestine Distribution of Heroin, its Discovery and Suppression", Journal of Political Economy, 76 (1), 78-90.

[26] Saffer H. and F. Chaloupka (1999), "The demand for illicit drugs", Economic Inquiry 37, 401-411.

[27] Skott P. and G.T. Jepsen (2002), "Paradoxical Effects of Drug Policy in a Model with Imperfect Competition and Switching Costs", Journal of Economic Behavior and Organisation, 48 (4), 335-354.

[28] United States Office of National Drug Control Policy (US-ONDCP) (2002), "National Drug Control Strategy", The White House, February 2002. 